Atmos. Chem. Phys., 13, 9401-9413, 2013

www.atmos-chem-phys.net/13/9401/2013/

doi:10.5194/acp-13-9401-2013

(c) Author(s) 2013. CC Attribution 3.0 License.

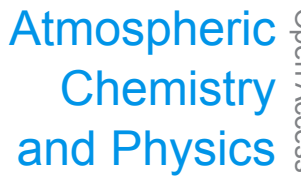

(c) (1)

\title{
Emission ratio and isotopic signatures of molecular hydrogen emissions from tropical biomass burning
}

\author{
F. A. Haumann ${ }^{1,2}$, A. M. Batenburg ${ }^{1,3}$, G. Pieterse ${ }^{1}$, C. Gerbig ${ }^{4}$, M. C. Krol ${ }^{1,5}$, and T. Röckmann ${ }^{1}$ \\ ${ }^{1}$ Institute for Marine and Atmospheric research Utrecht, Utrecht University, Utrecht, the Netherlands \\ ${ }^{2}$ Environmental Physics, Institute of Biogeochemistry and Pollutant Dynamics, ETH Zurich, Zurich, Switzerland \\ ${ }^{3}$ Aerosol Physics, Department of Applied Physics, University of Eastern Finland, Kuopio, Finland \\ ${ }^{4}$ Max Planck Institute for Biogeochemistry, Jena, Germany \\ ${ }^{5}$ Department of Meteorology and Air Quality, Wageningen University, Wageningen, the Netherlands
}

Correspondence to: F. A. Haumann (alexander.haumann@gmail.com)

Received: 27 February 2013 - Published in Atmos. Chem. Phys. Discuss.: 25 April 2013

Revised: 26 July 2013 - Accepted: 14 August 2013 - Published: 24 September 2013

\begin{abstract}
In this study, we identify a biomass-burning signal in molecular hydrogen $\left(\mathrm{H}_{2}\right)$ over the Amazonian tropical rainforest. To quantify this signal, we measure the mixing ratios of $\mathrm{H}_{2}$ and several other species as well as the $\mathrm{H}_{2}$ isotopic composition in air samples that were collected in the BARCA (Balanço Atmosférico Regional de Carbono na Amazônia) aircraft campaign during the dry season. We derive a relative $\mathrm{H}_{2}$ emission ratio with respect to carbon monoxide (CO) of $0.31 \pm 0.04 \mathrm{ppb} \mathrm{ppb}^{-1}$ and an isotopic source signature of $-280 \pm 41 \%$ in the air masses influenced by tropical biomass burning. In order to retrieve a clear source signal that is not influenced by the soil uptake of $\mathrm{H}_{2}$, we exclude samples from the atmospheric boundary layer. This procedure is supported by data from a global chemistry transport model. The $\Delta \mathrm{H}_{2} / \Delta \mathrm{CO}$ emission ratio is significantly lower than some earlier estimates for the tropical rainforest. In addition, our results confirm the lower values of the previously conflicting estimates of the $\mathrm{H}_{2}$ isotopic source signature from biomass burning. These values for the emission ratio and isotopic source signatures of $\mathrm{H}_{2}$ from tropical biomass burning can be used in future bottom-up and top-down approaches aiming to constrain the strength of the biomass-burning source for $\mathrm{H}_{2}$. Hitherto, these two quantities relied only on combustion experiments or on statistical relations, since no direct signal had been obtained from insitu observations.
\end{abstract}

\section{Introduction}

Molecular hydrogen $\left(\mathrm{H}_{2}\right)$ is the second most prominent reduced trace gas in the atmosphere with an average abundance of about 530 parts per billion (ppb) (Ehhalt, 1999; Novelli et al., 1999). Through its removal by reaction with the hydroxyl radical $(\mathrm{OH}), \mathrm{H}_{2}$ is indirectly linked to many other compounds, for example the important greenhouse gases methane $\left(\mathrm{CH}_{4}\right)$, tropospheric ozone, or carbon monoxide (CO). This is because the abundance of $\mathrm{OH}$ determines the removal of many pollutants and greenhouse gases, such as $\mathrm{CH}_{4}$, for which the Amazon region is a large source (Miller et al., 2007; Beck et al., 2012). Consequently, the oxidation of $\mathrm{H}_{2}$ implies an indirect greenhouse effect (Schultz et al., 2003; Derwent et al., 2006). This active role of $\mathrm{H}_{2}$ in tropospheric chemical cycles elicits a detailed assessment of the impacts of $\mathrm{H}_{2}$ emissions and an investigation and quantification of the individual terms in the global $\mathrm{H}_{2}$ budget.

Table 1 summarises the most important global tropospheric sources and sinks of $\mathrm{H}_{2}$ and their relative importance according to two recent studies (Ehhalt and Rohrer, 2009; Pieterse et al., 2013). The oxidation of methane and volatile organic compounds is the major source, followed by biomass burning, fossil-fuel combustion and nitrogen fixation over land and ocean with respective decreasing strength of the source. The major sink of atmospheric $\mathrm{H}_{2}$ is the uptake by the soil followed by the oxidation by $\mathrm{OH}$.

Crutzen et al. (1979) point out the importance of natural and anthropogenic vegetation fires as a source of many 
atmospheric trace gases, especially from tropical regions. Table 1 shows that about $20 \%$ of the total $\mathrm{H}_{2}$ source is ascribed to biomass burning. The major sources of $\mathrm{H}_{2}$ from biomass burning are vegetation fires in the tropical rainforests, biofuel burning, and fires in the savanna forests and grasslands (Andreae and Merlet, 2001). Minor contributors are the fires in extratropical forests and burning of agricultural waste (Andreae and Merlet, 2001). Table 2 lists three estimates of the $\mathrm{H}_{2}$ tropical biomass-burning source strength. Accordingly, about $3.9 \%$ to $8.4 \%$ of the total $\mathrm{H}_{2}$ emissions (Table 1) can be attributed to this source. Thus, human induced and natural biomass burning from tropical rainforests is a considerable source of $\mathrm{H}_{2}$ on the global scale, but an even more important and strong local source during the wildfire season. The model study by Pieterse et al. (2011), for example, shows a large plume of $\mathrm{H}_{2}$ over the Amazonian rainforest and other southern tropical areas in the austral spring and summer (cf. their Fig. 6). This illustrates that the local $\mathrm{H}_{2}$ emissions from biomass burning in the tropical rainforest can be a major seasonal contributor to the total source and might locally affect atmospheric levels of trace gas concentrations.

Global $\mathrm{H}_{2}$ emissions are often derived in a bottom-up approach using emission factors and the total biomass that is burned (Andreae and Merlet, 2001; Ehhalt and Rohrer, 2009) or by linking $\mathrm{H}_{2}$ emissions to the better constrained $\mathrm{CO}$ emissions via the $\mathrm{H}_{2} / \mathrm{CO}$ emission ratio (Price et al., 2007; Yver et al., 2011). Crutzen et al. (1979) and Novelli et al. (1999) use the latter approach with the $\mathrm{H}_{2}$ to carbon dioxide $\left(\mathrm{CO}_{2}\right)$ emission ratio. Emission ratios vary according to the type of biomass burned and the efficiency of the combustion process (Andreae and Merlet, 2001; Röckmann et al., 2010a). Consequently, estimates for the tropical rainforest differ from those for a boreal forest, for example. Bottom-up approaches to approximate the $\mathrm{H}_{2}$ source strength bear uncertainties arising from the emission ratio or factor, on the one hand, and the estimates of the amount of biomass burned or the $\mathrm{CO}$ and $\mathrm{CO}_{2}$ fluxes, on the other hand.

Top-down approaches were applied by Rhee et al. (2006) and Xiao et al. (2007). Rhee et al. (2006) used the stable isotopic composition together with a simple mass balance model. Xiao et al. (2007), on the other hand, did not use the isotopic composition but inverse modelling techniques. These methods are completely independent of emission ratios and may contribute to reducing the uncertainties. However, knowledge about the isotopic signatures of different sources needs to be improved to constrain the global budgets obtained from such an approach (Pieterse et al., 2011). So far, the only estimates of the biomass-burning source signature are obtained in laboratory experiments (Gerst and Quay, 2001; Röckmann et al., 2010a) or indirectly from in-situ observations using a statistical approach (Rhee et al., 2006). Röckmann et al. (2010a) discuss the differences between the contradicting values reported in these studies.

So far, no signal from biomass burning in the tropical rainforest has been obtained from in-situ measurements. In this
Table 1. Global tropospheric sources and sinks of $\mathrm{H}_{2}$ in $\mathrm{Tg} \mathrm{yr}^{-1}$ and approximate percentage of the total source or sink in brackets.

\begin{tabular}{lll}
\hline & $\begin{array}{l}\text { Ehhalt and Rohrer } \\
(2009)\end{array}$ & $\begin{array}{l}\text { Pieterse et al. } \\
(2013)^{*}\end{array}$ \\
\hline $\begin{array}{l}\text { Sources } \\
\text { Photochem. production } \\
\text { (by CH}\end{array}$ \& VOC) & $41 \pm 11(54 \%)$ & $37 \pm 4(48 \%)$ \\
$\quad \begin{array}{l}\text { Biomass burning } \\
\text { Fossil fuel combustion }\end{array}$ & $15 \pm 6(20 \%)$ & $15 \pm 4(19 \%)$ \\
$\mathrm{N}_{2}$ fixation, ocean & $6 \pm 3(8 \%)$ & $17 \pm 4(22 \%)$ \\
$\mathrm{N}_{2}$ fixation, land & $3 \pm 2(4 \%)$ & $3 \pm 2(4 \%)$ \\
\hline Total & $76 \pm 14$ & $77 \pm 16$ \\
\hline Sinks & $60_{-20}^{+30}(76 \%)$ & $53 \pm 4(70 \%)$ \\
$\quad$ Soil deposition & $19 \pm 5(24 \%)$ & $23 \pm 2(30 \%)$ \\
$\quad$ Oxidation by $\mathrm{OH}$ & $79_{-20}^{+30}$ & $76 \pm 6$ \\
\hline Total & & \\
\hline
\end{tabular}

* Their scenario S3c.

study, we retrieve this signal in air samples collected during the BARCA (Balanço Atmosférico Regional de Carbono na Amazônia) flight campaign over the Amazonian rainforest. We derive the $\mathrm{H}_{2}$ / CO emission ratio directly from measurements of the mixing ratio and compare them to former estimates. Further, we characterise the isotopic signature of the biomass-burning source. These two estimates support both bottom-up and top-down approaches to quantify the contribution of tropical biomass burning to the global and local $\mathrm{H}_{2}$ budget.

After a short description of the measurement campaign and the air sample collection, we describe the measurement techniques to derive the chemical compounds and the isotopic composition in Sect. 2. The $\mathrm{H}_{2} / \mathrm{CO}$ emission ratio is derived and discussed in Sect. 3, and the isotopic composition of $\mathrm{H}_{2}$ from biomass burning is studied in Sect. 4. In Sect. 5, we compare our results to output from a global chemistry transport model, TM5 (Krol et al., 2005; Pieterse et al., 2013).

\section{Data and methodology}

The samples that were collected over the Amazonian tropical rainforest have been analysed in two different laboratories for mixing ratios of several trace gases (Max Planck Institute for Biogeochemistry, Jena; hereafter MPI-BGC) and the isotopic composition of $\mathrm{H}_{2}$ (Institute for Marine and Atmospheric Research Utrecht, Utrecht; hereafter IMAU). In this section, we provide a brief description on how the datasets were obtained. The $\mathrm{CO}$ and $\mathrm{H}_{2}$ mixing ratios as well as the $\mathrm{H}_{2}$ isotope data used for our analysis in this study are available in the Supplement. 
Table 2. Estimates of the tropical biomass-burning $\mathrm{H}_{2}$ source strength, emission ratio, and isotopic signature.

\begin{tabular}{|c|c|c|c|c|}
\hline & $\begin{array}{l}\mathrm{H}_{2} \text { Flux } \\
{\left[\operatorname{Tg~yr}^{-1}(\%)\right]}\end{array}$ & $\begin{array}{l}\mathrm{H}_{2} / \mathrm{CO} \text { by mass } \\
{\left[\mathrm{g} \mathrm{mol}^{-1} / \mathrm{g} \mathrm{mol}^{-1}\right]}\end{array}$ & $\begin{array}{l}\Delta \mathrm{H}_{2} / \Delta \mathrm{CO} \\
{\left[\mathrm{ppbppb}^{-1}\right]}\end{array}$ & $\begin{array}{l}\delta \mathrm{D}_{\mathrm{bb}} \\
{[\% \mathrm{o}]}\end{array}$ \\
\hline Laursen et al. (1992) & $\left.3.0(3.9 \%)^{\mathrm{a}}\right)^{\mathrm{b}}$ & - & - & - \\
\hline Andreae and Merlet (2001) & $5.1\left(6.7 \%^{\mathrm{a}}\right)^{\mathrm{c}}$ & $0.037 \pm 0.005^{\mathrm{e}}$ & $0.52 \pm 0.07^{\mathrm{e}}$ & - \\
\hline Gerst and Quay (2001) & - & - & - & $\left(-290 \pm 60^{g}\right)$ \\
\hline Rhee et al. (2006) & - & $0.036 \pm 0.007^{\mathrm{e}}$ & $0.5 \pm 0.1$ & $-30 \pm 20$ \\
\hline Röckmann et al. (2010a) & - & - & - & $\left(-262 \pm 27^{g}\right)$ \\
\hline Yver et al. (2011) & $\left.6.4(8.4 \%)^{\mathrm{a}}\right)^{\mathrm{d}}$ & $\left(0.02^{\mathrm{f}, \mathrm{g}}\right)$ & $\left(0.28^{\mathrm{e}, \mathrm{f}, \mathrm{g}}\right)$ & - \\
\hline Vollmer et al. (2012) & - & $\left(0.018 \pm 0.004^{\mathrm{e}, \mathrm{g}}\right)$ & $\left(0.25 \pm 0.05^{\mathrm{g}}\right)$ & - \\
\hline This study & - & $0.022 \pm 0.002$ & $0.31 \pm 0.04$ & $-280 \pm 41$ \\
\hline
\end{tabular}

a With respect to total source in Table 1 ,

b $1975-1980$,

c late 1990 s,

d mid-2006-mid-2009,

e calculated from the referenced values,

$\mathrm{f}$ from Hauglustaine and Ehhalt (2002),

$\mathrm{g}$ global estimate.

\subsection{Sample acquisition}

Air samples were collected during the first of the two aircraft measurement campaigns of the BARCA project as part of the Large Scale Biosphere-Atmosphere (LBA) program. In general, the BARCA-LBA project aimed at providing in-situ measurements of mainly carbon fluxes from the biosphere of the tropical rainforest to the atmosphere on a scale between global and local.

The BARCA-A campaign was performed towards the end of the biomass-burning season, in November and December 2008. The second part of the program, BARCA-B, was carried out at the end of the wet season, in May 2009. As we are interested especially in the biomass-burning signal, we only analysed samples from the BARCA-A flights for this study. Figure 1 shows an overview of the biomass burning conditions during the BARCA-A period. The fire radiative power from wildfires over South America (Fig. 1a) can be considered as proportional to the biomass burned. The data is a satellite product from the MODIS instrument and obtained from the Global Fire Assimilation System (GFASv1.0) by Kaiser et al. (2012). It shows extensive fires in the eastern part of the Amazon Basin close to the coast. Further, the European Centre of Medium Range Weather Forecast (ECMWF) ERA-Interim reanalysis (Dee et al., 2011) $800 \mathrm{hPa}$-level mean wind vectors illustrate the largescale circulation pattern. Easterly or north-easterly winds imply an advection of air masses from the major biomassburning region over the interior of the continent and the sampling region. Figure $1 \mathrm{~b}$ shows an enlargement of the box in Fig 1a. The coloured area in Fig. 1b shows the estimated GFASv1.0 $\mathrm{H}_{2}$ emissions that are associated with the biomass burning. These $\mathrm{H}_{2}$ emissions were retrieved by scaling the burned matter with emission factors from Andreae and Merlet (2001) for tropical rainforest (Kaiser et al., 2012).
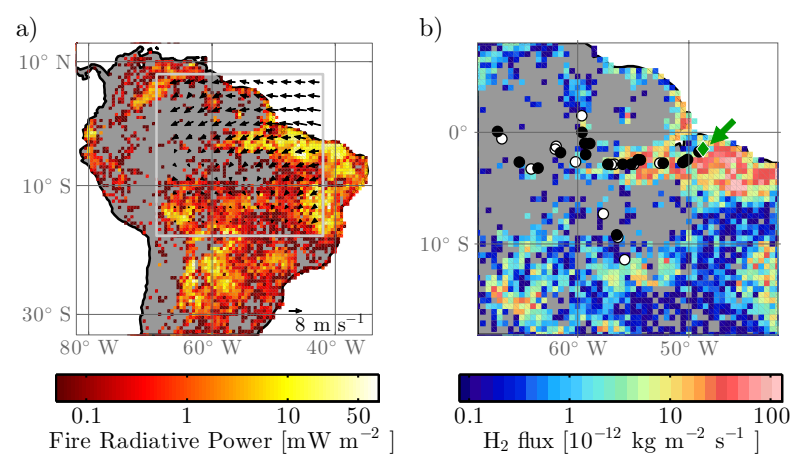

Fig. 1. Biomass-burning sources in the sampling area from November to December 2008. (a) Mean GFASv1.0 fire radiative power from wildfires (Kaiser et al., 2012) and ERA-Interim reanalysis wind vectors on the $800 \mathrm{hPa}$ level (Dee et al., 2011). (b) Enlargement of the box in (a). Mean GFASv1.0 scaled $\mathrm{H}_{2}$ emissions from biomass burning (Kaiser et al., 2012) and BARCA-A sample sites (circles) used in this study (black: above $1100 \mathrm{~m}$ a.s.l.; white: below $1100 \mathrm{~m}$ a.s.l.; and green (highlighted by the arrow): highly contaminated sample in Figs. 2 and 3).

Several flight tracks span more than $2000 \mathrm{~km}$ of the Amazon Basin that were influenced by air masses from the regions of extensive biomass burning. Samples were taken in vertical profiles along the tracks from near-surface up to more than $4000 \mathrm{~m}$ a.s.l. in the atmospheric boundary layer and the lower free troposphere above. The samples that we analyse in this study are indicated by circles in Fig. 1b. Black circles indicate high-altitude samples (above $1100 \mathrm{~m}$ a.s.l.) and white circles low-altitude samples (below $1100 \mathrm{~m}$ a.s.l.). They were all either collected directly in the wildfire region visible in Fig. 1 or downwind of this region. The area where the samples were collected and the region to the east are mostly covered by dense forest (Saatchi et al., 2007; 
Simon et al., 2009). Thus, we expect a biomass-burning influence mainly from $\mathrm{C} 3$ plants. In the south-eastern corner of the enlarged box in Fig. 1b, however, the dominant vegetation cover is savanna grassland (Saatchi et al., 2007; Simon et al., 2009). This could have a small influence on some of the samples. Andreae et al. (2012) and Beck et al. (2012) give more details on the sampling and a description of the flight tracks. Some of the samples were collected directly inside biomass-burning plumes along the tracks what gives us the possibility to distinguish samples with high contamination.

Next to the air sampling, numerous chemical species were analysed continuously on the aircraft (Chen et al., 2010). In this project, we have only used data from the air samples analysed in the laboratories. A more in depth analysis of $\mathrm{CO}$ and aerosols as well as $\mathrm{CH}_{4}$ from both flight campaigns is provided by Andreae et al. (2012) and Beck et al. (2012), respectively.

\subsection{Mixing ratio measurements}

The 174 flask samples taken during the BARCA-A campaign have been measured for the mixing ratio of several gases (among others $\mathrm{CO}, \mathrm{CO}_{2}, \mathrm{CH}_{4}$, and $\mathrm{H}_{2}$ ) at the MPI-BGC Gaslab. Measurements in the laboratory were conducted 120 to 300 days after the sampling (Andreae et al., 2012). Between the time of sampling and the measurements the samples were kept in 11 borosilicate 3.3 glass flasks which were sealed with PCTFE valves (Batenburg et al., 2011; Andreae et al., 2012). In order to avoid any photochemical production of $\mathrm{H}_{2}$, the flasks were enclosed by black flexible tubes and stored in closed metal boxes. The stabilities of several species were tested at the MPI-BGC Gaslab. Most of the species showed no significant drift except for $\mathrm{CO}$ which increased by 2.6 to $6.5 \mathrm{ppb}$ during the storage period (Andreae et al., 2012). Flask analysis results were combined with the continuous data (tracers, meteorological parameters, position) using weighting functions that mimic the temporal averaging during the flask sampling process (Chen et al., 2012). For a number of tracers measured continuously as well as in the flask samples comparisons resulted in good agreement (cf. Andreae et al., 2012; Beck et al., 2012).

In this study, we use $\mathrm{H}_{2}$ and $\mathrm{CO}$ mixing ratios of 72 samples for which data was available. These were determined using a Trace Analytical Reduction Gas Analyser (RGA), which uses gas chromatographic separation with subsequent $\mathrm{HgO}$ reduction and photometric UV detection of $\mathrm{Hg}$. Each sample analysis was bracketed by a working tank analysis. The response of the RGA was determined on a daily basis using multiple standards bracketing the range of sample mixing ratios. $\mathrm{CO}$ values are reported on the WMO $2004 \mathrm{CO}$ mole fraction scale (Novelli et al., 2003). Note that CO values from flask sample analysis were not corrected for the offset of $6.3 \pm 2.1 \mathrm{ppb}$ compared to the continuous measurements (Andreae et al., 2012). This offset is likely due to a temporal increase between sample collection and anal- ysis. However, it has no significant impact on the results for emission ratios. In contrast to the $\mathrm{CO}$ values, $\mathrm{H}_{2}$ values are reported on the CSIRO94 calibration scale, which is also used by the Advanced Global Atmospheric Gases Experiment (AGAGE) network (Simmonds et al., 2000). Note that this is different to the new $\mathrm{WMO}_{2}$ scale maintained at MPI-BGC (Jordan and Steinberg, 2011). The range of the $\mathrm{H}_{2}$ and $\mathrm{CO}$ mixing ratios in the samples that we analyse in this study is within the calibrated range of the RGA and the non-linearity was explicitly corrected for by a suite of reference gases.

\subsection{Hydrogen stable isotopic composition}

The fractionation of the two isotopes is coupled to the process in which $\mathrm{H}_{2}$ is involved. Reciprocally, it is often possible to identify a process from an air sample once the isotopic characteristics are known. The method of detecting sources and sinks by retrieving their isotopic hydrogen signature was successfully applied in many studies before (e.g. Gerst and Quay, 2001; Röckmann et al., 2010a; Batenburg et al., 2011, 2012).

We analysed 39 samples from the BARCA-A campaign for the $\mathrm{H}_{2}$ isotopic composition in the isotope laboratory at the IMAU. The measurement of the $\mathrm{H}_{2}$ isotopic composition with a gas-chromatography isotope-ratio mass spectrometer system (GC-IRMS) followed the procedure developed by Rhee et al. (2004) and updated by Röckmann et al. (2010b) and Batenburg et al. (2011, 2012): at first $\mathrm{H}_{2}$ was purified in three steps. A sample volume of about $750 \mathrm{ml}$ was filled with the air sample to a pressure of about $600 \mathrm{hPa}$. Subsequently, the sample was exposed to a "cold head" (of about $40 \mathrm{~K}$ ) where all gases except for the most volatile ones condensed. The remaining gases were flushed by a helium $(\mathrm{He})$ carrier gas into a $5 \AA$ molecular-sieve pre-concentration trap that was immersed in liquid nitrogen (cooled down to the $\mathrm{N}_{2}$ triple point by pumping on the gas phase) to collect the $\mathrm{H}_{2}$. The gases were then flushed to a cryo-focus trap that was immersed in liquid nitrogen $(77 \mathrm{~K})$ and afterwards to a $\mathrm{GC}$ column at $323 \mathrm{~K}$. This procedure separated $\mathrm{H}_{2}$ from any other gas. Between the sample measurements the cold head, the pre-concentration trap, the cryo-focus trap, and the GC column were heated in order to avoid any contamination from the previous sample.

The isotopic composition was determined online from the purified $\mathrm{H}_{2}$ by an IRMS. Here, it is reported in the common $\delta$-notation, defined as

$\delta \mathrm{D}=\left(\frac{R_{\mathrm{SA}}}{R_{\mathrm{ST}}}-1\right) 1000 \%$,

where $R$ denotes the ratio of the "heavy" isotope, deuterium (D), to the "light" isotope $(\mathrm{H})$ and the subscripts SA and ST abbreviate the sample and the standard, respectively. The international standard $\mathrm{D} / \mathrm{H}$ ratio is the one of Vienna Standard Mean Ocean Water (VSMOW) with a value of 
$155.76 \pm 0.08 \mathrm{ppm}$ (de Wit et al., 1980; Gonfiantini et al., 1993). The $\mathrm{H}_{2}$ sample peak was preceded by seven injections of our $\mathrm{H}_{2}$ laboratory working gas and followed by two more injections of the reference gas into the IRMS from a custom made open split system (Röckmann et al., 2003).

In total, the samples were measured on ten different days. On each of these days, we determined the $\mathrm{H}_{2}$ isotopic composition of two different laboratory reference air cylinders with known values of $\delta \mathrm{D}(198.2 \pm 0.5 \%$ and $207.0 \pm 0.3 \%$ o). Additionally, a blank measurement was performed every day. These measurements were used to monitor the performance of the system and calibrate the results. The mean standard deviation obtained from the measurements of the two laboratory reference air cylinders was $6.7 \%$ which was slightly higher than the $4.5 \%$ reported by Batenburg et al. (2011). This larger scatter might have been caused by small fluctuations in the system performance or technical replacements in the set up. The area of the blank peak in the chromatogram was on average $1.7 \%$ of the sample peak area, so less than the $4 \%$ in the experiments by Batenburg et al. (2011), indicating an even smaller systematic error.

The $\delta \mathrm{D}$ values retrieved for the samples were calibrated using the two measured $\delta \mathrm{D}$ values from the laboratory reference-air flasks. We smoothed these reference values with a five-day moving average (cf. Batenburg et al., 2011). However, we did not apply the empirical bias correction $(9.5 \%$ ) and scale contraction (1.0613) factors determined by Batenburg et al. (2011). An analysis of another reference gas that was measured as well on a daily basis revealed that its measured $\delta \mathrm{D}$ value without any correction applied was very close (the difference is $4 \%$ ) to the certified value by the manufacturer (Messer Griesheim) and within the provided range of uncertainty. However, if we had applied the scale contraction factor, there would have been a large deviation from the certified value (outside the uncertainty range). The empirical bias correction factor had a smaller effect, but the deviation from the certified value was still larger than without this correction. Not using this bias correction factor was further motivated by the facts that no cause of the sudden increase in the values measured by Batenburg et al. (2011) had been determined, and that further technical changes were made on the system set up since this value had been determined. We tested the results presented in this study by applying all corrections as well and found that they are still within the range of uncertainty that we provide in Sects. 3 and 4.

As a consequence of the above discussion, the sample measurements were calibrated as follows:

$\delta \mathrm{D}_{\mathrm{c}_{1,2}}=\delta \mathrm{D}_{\mathrm{s}}+\left(\delta \mathrm{D}_{R_{1,2}}-\delta \mathrm{D}_{\mathrm{r}_{1,2}}\right)$,

where $\delta \mathrm{D}_{\mathrm{s}}$ and $\delta \mathrm{D}_{\mathrm{r}_{1,2}}$ are the measured values from the sample and the two laboratory reference gas flasks, and $\delta \mathrm{D}_{R_{1,2}}$ are the known reference values that were smoothed with the five-day moving average. The final calibrated $\delta \mathrm{D}$ value is, then, the arithmetic mean of the two corrected values obtained from Eq. (2) $\left(\overline{\delta \mathrm{D}_{\mathrm{c}_{1,2}}}\right)$.

\subsection{Model simulation}

In order to support our analysis applied in Sects. 3 and 4, we performed a simulation with the global chemistry transport model TM5 (Tracer Model, version 5) (Krol et al., 2005; Huijnen et al., 2010). We used the two-way nested set up developed by Krol et al. (2005) for a high-resolution zoom over the Amazon Basin. Resolution increases from $6^{\circ} \times 4^{\circ}$ (longitude $\times$ latitude), through $3^{\circ} \times 2^{\circ}$ to $1^{\circ} \times 1^{\circ}$. In the vertical the model consists of 25 hybrid levels.

This full chemistry model was forced with scaled surface emissions of the year 2003 from Schultz and Stein (2006) as described by Pieterse et al. (2011). These emissions were fixed throughout the simulation and did not vary from one year to the other. Note that in this model configuration the surface emission data from Schultz and Stein (2006) are different from those shown in Fig. 1 for illustration. The meteorological forcing was the ECMWF ERA-Interim reanalysis data (Dee et al., 2011). For a detailed description of parameterisations applied, the $\mathrm{H}_{2}$ chemistry in the model, and a model evaluation, we refer the reader to Pieterse et al. (2013).

In this study, we investigate the mean model output for the same season as the BARCA-A campaign (November and December) in order to resemble the meteorological conditions. We only use data from the fifth year of model integration. Even though surface fluxes are not from the year 2008, the model provides sufficient information on the relative strength of the source to analyse the general biomass-burning signal in this region. We will use vertical profiles of $\mathrm{H}_{2}$ and $\delta \mathrm{D}$ from the model simulation to compare the effect of vertical transport by turbulent mixing and convection to the observations.

\section{Hydrogen to carbon monoxide ratio from biomass burning}

Distinct emission ratios between several atmospheric trace gases are related to different combustion processes. These relations can be used to identify samples that are strongly contaminated by a certain process or to estimate the strength of the source of one species if the other one is known.

Comparing the $\mathrm{H}_{2}$ and $\mathrm{CO}$ mixing ratios of the 72 BARCA-A samples available, we obtain a significant Pearson correlation coefficient of about 0.64 (at a $99 \%$ confidence level using a $t$ test). Hence, an analysis of the apparent pyrogenic signal seems promising. No correlation between $\mathrm{H}_{2}$ and $\mathrm{CO}_{2}$ or between $\mathrm{H}_{2}$ and $\mathrm{CH}_{4}$ is present. Therefore, we derive the emission ratio between $\mathrm{H}_{2}$ and $\mathrm{CO}$. Values are commonly reported as elevations over a typical background mixing ratio, thus as $\Delta \mathrm{H}_{2}=\mathrm{H}_{2}-\mathrm{H}_{2 \text {, bg and }}$ $\Delta \mathrm{CO}=\mathrm{CO}-\mathrm{CO}_{\mathrm{bg}}$. In this study, however, we do not use the background mixing ratio to estimate the $\Delta \mathrm{H}_{2} / \Delta \mathrm{CO}$ ratio but the slope of the regression line through the measured mixing ratios of $\mathrm{H}_{2}$ and $\mathrm{CO}$. Therefore, we need to assume that any deviations from the background mixing ratio of the 
considered species almost solely result from biomass burning and all other source and sink terms are minor. We will later discuss to what extent this assumption is valid for our set of samples and how we can reduce potential interferences. Moreover, the assumption of a single source in the samples translates to a constant background value for both species. During the BARCA-A campaign the background mixing ratio of $\mathrm{CO}$ is about $79 \pm 7 \mathrm{ppb}$ (cf. Andreae et al., 2012). There is no estimate for the background mixing ratio of $\mathrm{H}_{2}$ for the BARCA-A period. Here, we will thus use the $\mathrm{CO}$ background mixing ratio and our value for the $\Delta \mathrm{H}_{2} / \Delta \mathrm{CO}$ ratio to estimate the $\mathrm{H}_{2}$ background concentration as well.

Figure 2 shows the relation between the $\mathrm{H}_{2}$ and $\mathrm{CO}$ mixing ratios determined from the BARCA-A samples. In order to retrieve a $\Delta \mathrm{H}_{2} / \Delta \mathrm{CO}$ ratio from all available samples (coloured and grey), the Williamson-York bivariate total least squares linear regression algorithm suggested by Cantrell (2008) has been applied. The iterative algorithm takes the statistical errors of both the $\mathrm{H}_{2}$ and $\mathrm{CO}$ mixing ratios into account. The resulting $\Delta \mathrm{H}_{2} / \Delta \mathrm{CO}$ ratio is $0.29 \pm 0.05$. Despite the significant correlation, there is a large scatter between these samples, especially for lower $\mathrm{H}_{2}$ mixing ratios. This probably results from other sinks or sources that influence the $\mathrm{H}_{2}$ or $\mathrm{CO}$ mixing ratios.

Next to the biomass-burning source, the uptake of $\mathrm{H}_{2}$ by the soil has the largest influence on the mixing ratio in the tropics (cf. Fig. 8 in Pieterse et al., 2011). Presumably, the effect of this sink is particularly strong in the lower atmospheric boundary layer by persistent mixing of air masses to the surface. Consequently, here, we expect the strongest signals of these sinks. In contrast, the source signal from the vegetation fires can reach high up in the atmosphere due to convection. This high uplift of air masses influenced by the biomass-burning source is caused either by the heat produced by these extensive fires themselves, by natural convection occurring at this time of the year, or by a combination of these two effects. During November and December - at the end of the dry season - the atmospheric stratification over the Amazon Basin is mostly unstable and frequent convection is very likely to occur (Fu et al., 1999; Fu and Li, 2004). Also the circulation pattern shown in Fig. 1a, that is dominantly easterly, suggests a transition period to the wet season and favourable conditions for convection.

In order to be consistent throughout this study, including the derivation of the isotopic signature, we will proceed to only analyse those 39 samples for which the isotopic composition was measured as well. Figure 2 shows these rather arbitrarily selected samples (colour) spread along the regression line of all collected samples. The selected samples cover the full horizontal and vertical space of the sampling region (cf. Fig. 1) and we selected them to be representative in terms of their range in the $\mathrm{H}_{2}-\mathrm{CO}$ space.

At this point, the fact that the sampling during the flight campaign was carried out in vertical profiles is very useful. A separation of the samples into two groups, higher and lower than $1100 \mathrm{~m}$ a.s.l. (red and blue in Fig. 2, respectively), visualises the effect of altitude in the measurements. We have chosen this altitude as it provides the clearest separation between the samples and the correlation coefficient for each group of samples is optimal. The value of about $1000 \mathrm{~m}$ above ground level is consistent with the approximate height of a daytime convective mixed boundary layer over land surfaces (cf. e.g. Stull, 1988). Samples closer to the ground have much lower $\mathrm{H}_{2}$ mixing ratios and carry interfering signals of the biomass-burning source and the soil uptake.

The highest 20 samples (red in Fig. 2) are very likely almost solely influenced by the biomass-burning source, reflected by a very high correlation coefficient of about 0.95 (significant at a $99 \%$ confidence level). However, one should notice that the sample with very high mixing ratios, visible in Fig. 2, strongly increases the correlation. Removing this sample from the selection yields still a significant correlation coefficient of 0.85 . Beck et al. (2012) also report a very high contamination by the biomass-burning source in this specific sample. Considering its location highlighted in Fig. 1, we are confident that this sample was taken in a large biomass-burning plume. Thus, we incorporate this sample in the further analysis.

The slope of the regression line through the samples above 1100 m a.s.l. (red in Fig. 2) with a value of $0.31 \pm 0.04$ is our best estimate of the $\Delta \mathrm{H}_{2} / \Delta \mathrm{CO}$ ratio of biomass burning over tropical rainforest. Excluding the discussed high mixing ratio sample results in a ratio that is still within the given range of uncertainty. The $\mathrm{H}_{2}$ background mixing ratio using the regression line through these high altitude samples at the intercept with the estimate of $79 \pm 7 \mathrm{ppb}$ (cf. Andreae et al., 2012) for the CO background mixing ratio is about $521 \pm 7 \mathrm{ppb}$.

The correlation between $\mathrm{H}_{2}$ and $\mathrm{CO}$ is most significant for the higher altitude samples. However, also the 14 samples below $1100 \mathrm{~m}$ a.s.l. - for which an interference of the soilsink signal is likely - carry a biomass-burning signature (blue in Fig. 2). The correlation coefficient for these samples has a significant value of 0.86 (at a $99 \%$ confidence level). The resulting regression line has a slope of $0.21 \pm 0.04$. Closer to the ground $\mathrm{H}_{2}$ is taken up by the soil lowering the $\mathrm{H}_{2}$ values in these samples and, thus, altering their $\Delta \mathrm{H}_{2} / \Delta \mathrm{CO}$ ratio.

A group of five samples with very low $\mathrm{H}_{2}$ mixing ratios (below $510 \mathrm{ppb}$ ) in the lower boundary layer (below $300 \mathrm{~m}$ a.s.1.) is highlighted in green in Fig. 2. The low values are likely the result of a weak biomass-burning source signature and a very strong influence of the soil sink. This could be caused by little advection of contaminated air into this region and/or a strong mixing in the lower boundary layer that enhances the influence of the soil uptake. Our interpretation is supported by the fact that these samples are among those collected very close to ground in the atmospheric surface layer (about 60 to $190 \mathrm{~m}$ above ground level). Consequently, we excluded the five samples marked (green) in Fig. 2 from the 


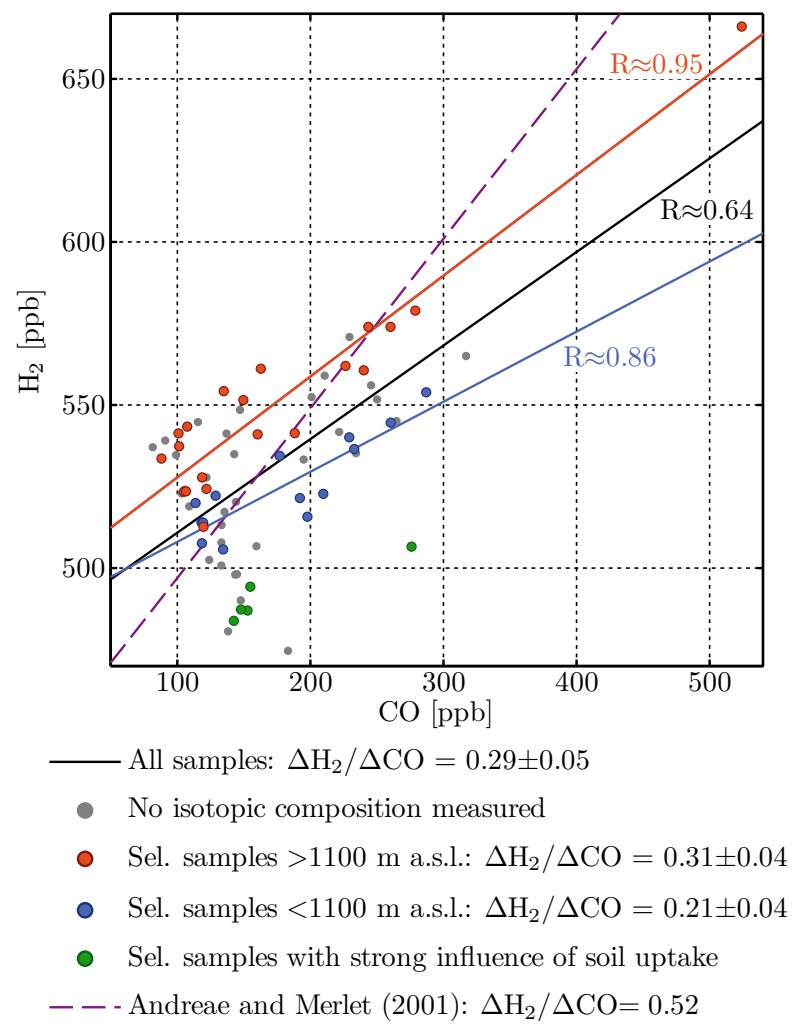

Fig. 2. Relation between $\mathrm{H}_{2}$ and $\mathrm{CO}$ mixing ratios of BARCA-A samples. The bivariate total least squares regression line through all samples (coloured and grey) is shown in black. Those samples where the $\mathrm{H}_{2}$ isotopic composition was determined are shown in colour and all others are shown in grey. Coloured samples are separated in three groups: (red) high altitude samples (above $1100 \mathrm{~m}$ a.s.1.) with biomass burning as major signal; (blue) low altitude samples (below $1100 \mathrm{~m}$ a.s.l.) contaminated by biomass burning but influenced by soil uptake; and (green) very low $\mathrm{H}_{2}$ mixing ratio (not influenced by biomass burning). The slope of the bivariate total least squares regression line for all biomass burning influenced samples is also given. The purple dashed line shows the estimate of Andreae and Merlet (2001) for biomass burning in tropical rainforest.

analysis (they are only considered for the black regression line in Fig. 2).

Considering only the selected samples that show a clear biomass-burning signal at higher altitudes, the relations between $\mathrm{H}_{2}$ and $\mathrm{CH}_{4}$ and between $\mathrm{H}_{2}$ and $\mathrm{CO}_{2}$ are still not significant. This makes it impossible to derive reliable estimates of the respective emission ratios. Probably, there are other sources and sinks of $\mathrm{CH}_{4}$ and $\mathrm{CO}_{2}$ that are rather dominant locally and mask the biomass-burning signal in some samples.

Beck et al. (2012) report a significant relation between CO and $\mathrm{CH}_{4}$ for all BARCA-A samples analysed in the laboratory of the MPI-BGC. They found that several samples have a $\Delta \mathrm{CO}$ to $\Delta \mathrm{CH}_{4}$ ratio that is close to that of biomass burn- ing. Among these samples is the mentioned single outlier in our Fig. 2 that has been shown to be strongly contaminated by a biomass-burning plume (Beck et al., 2012). Its location very close to the regression line of the samples in the upper convective atmospheric layer in Fig. 2 confirms our approach to separate the samples.

Vollmer et al. (2012) summarise different $\Delta \mathrm{H}_{2} / \Delta \mathrm{CO}$ and $\Delta \mathrm{H}_{2} / \Delta \mathrm{CH}_{4}$ ratios from biomass burning that can be found in literature. They derive an average $\Delta \mathrm{H}_{2} / \Delta \mathrm{CO}$ ratio $0.25 \pm 0.05$ and an average $\Delta \mathrm{H}_{2} / \Delta \mathrm{CH}_{4}$ ratio of 3.6. Their $\Delta \mathrm{H}_{2} / \Delta \mathrm{CO}$ ratio is close to the value derived by Hauglustaine and Ehhalt (2002) that was adopted by Yver et al. (2011) for an estimation of the tropical $\mathrm{H}_{2}$ source strength (cf. Table 2).

Most estimates of the emission ratios, including those by Vollmer et al. (2012) and Hauglustaine and Ehhalt (2002), represent global values. Biomass-burning characteristics in the tropical rainforest might, however, differ considerably from those in other regions. Andreae and Merlet (2001) address these deviations and list estimated emission factors of each species (compared to the burned dry matter) from tropical rainforests. We have converted these estimates to the relative $\Delta \mathrm{H}_{2} / \Delta \mathrm{CO}$ emission ratio of $0.52 \pm 0.07$ in Table 2 . This result is much higher than those by Vollmer et al. (2012) and Hauglustaine and Ehhalt (2002) on a global scale, and also the $\Delta \mathrm{H}_{2} / \Delta \mathrm{CH}_{4}$ ratio derived from Andreae and Merlet (2001) yields a higher value $(9.6 \pm 2.3)$ than the global scale estimate.

Higher emission ratios from burning of tropical plants mainly result from a comparably higher $\mathrm{H}_{2}$ emission factor. A factor that could possibly alter the $\Delta \mathrm{H}_{2} / \Delta \mathrm{CO}$ ratio regionally is the combustion efficiency. However, Röckmann et al. (2010a) did not find any significant relation. In contrast, Popa et al. (2011) find that the combustion efficiency might well influence the $\mathrm{H}_{2}$ / CO ratio of fossil fuel combustion considerably. To what degree it might alter the biomassburning signal is not well understood.

Rhee et al. (2006) report a biomass-burning signal that is detected through an indirect analysis of air samples collected close to the tropical tropopause. Even though no significant direct signal of a biomass-burning source was visible in the $\mathrm{H}_{2}$ mixing ratios of these samples, both the $\Delta \mathrm{H}_{2} / \Delta \mathrm{CO}$ ratio and the isotopic signature were retrieved using the signal that could be seen in peaks of the $\mathrm{CO}$ mixing ratios. They interpreted the missing higher values of $\mathrm{H}_{2}$ as an overlapping effect from the biomass-burning source and the soil sink. The resulting estimate of the $\Delta \mathrm{H}_{2} / \Delta \mathrm{CO}$ ratio from biomass burning over the tropics ranges between 0.4 and 0.6 in their Fig. 4a. Additionally, the findings of Rhee et al. (2006) imply lower $\Delta \mathrm{H}_{2} / \Delta \mathrm{CO}$ ratios for savanna and extratropical forests than for the tropical forests.

Our $\Delta \mathrm{H}_{2} / \Delta \mathrm{CO}$ ratio with a value of $0.31 \pm 0.04$ is significantly lower than those derived from the analysis by Rhee et al. (2006) and Andreae and Merlet (2001) for tropical rainforests (cf. Table 2). However, it is more in line with - 
though slightly higher than - the upper-end global estimates summarised by Vollmer et al. (2012) and the estimate by Hauglustaine and Ehhalt (2002). Our direct measurements from a comparatively large set of samples thus support the lower $\Delta \mathrm{H}_{2} / \Delta \mathrm{CO}$ estimates.

\section{Hydrogen isotopic signature from biomass burning}

It is known that $\mathrm{H}_{2}$ from biomass burning is depleted in $\delta \mathrm{D}$ relative to the global average isotopic composition of about 130\%o (Gerst and Quay, 2001; Röckmann et al., 2010a). However, its precise isotopic signature from biomass burning is still under discussion.

In this study, we derive the $\delta \mathrm{D}_{\mathrm{bb}}$ for tropical rainforest fires applying the selection procedure presented in Sect. 3 to the isotopic composition. The clearest biomass-burning signature should, consequently, be visible in the higher altitude samples. Figure 3 shows a Keeling plot of the inverse $\mathrm{H}_{2}$ mixing ratios and the $\delta \mathrm{D}$ values measured at the IMAU laboratory for all three groups of samples. As in Fig. 2, they are clearly separated:

1. The high-altitude samples bear a biomass-burning signature, thus they show a more depleted $\delta \mathrm{D}$ for higher $\mathrm{H}_{2}$ mixing ratios (red).

2. The samples in the boundary layer carry a similar signature but are overall shifted towards lower $\mathrm{H}_{2}$ mixing ratios (blue).

3. As we expected, all samples that are probably strongly influenced by the soil uptake and are collected within the surface layer have high $\delta \mathrm{D}$ values (green).

These observations confirm our approach and interpretation in Sect. 3.

Pearson's correlation coefficient between the inverse $\mathrm{H}_{2}$ mixing ratio and the $\delta \mathrm{D}$ values for all samples at higher altitudes (red in Fig. 3) is -0.89 at a $99 \%$ confidence level. Omitting the highly depleted sample yields a lower but still significant correlation of -0.82 . Using the same bivariate total least squares linear regression algorithm as in Sect. 3 (Cantrell, 2008), we are able to estimate the $y$ axis intercept of these samples. The resulting $\delta \mathrm{D}_{\mathrm{bb}}$ signature from the tropical rainforest is $-280 \pm 41 \%$.

The highly depleted sample in the lower left corner of Fig. 3 is the same sample as the one in the upper right corner of Fig. 2. This confirms the strong biomass-burning signature in this sample detected in Sect. 3 and by Beck et al. (2012). The signature without this sample would result in a signature of $-289 \%$ and, thus, has only a minor effect on the result. Moreover, this sample has the largest offset to the regression line. The offset might not only be due to the uncertainty of the measurement but could also include the effect of the combustion efficiency (see below) on the $\delta \mathrm{D}$ value.

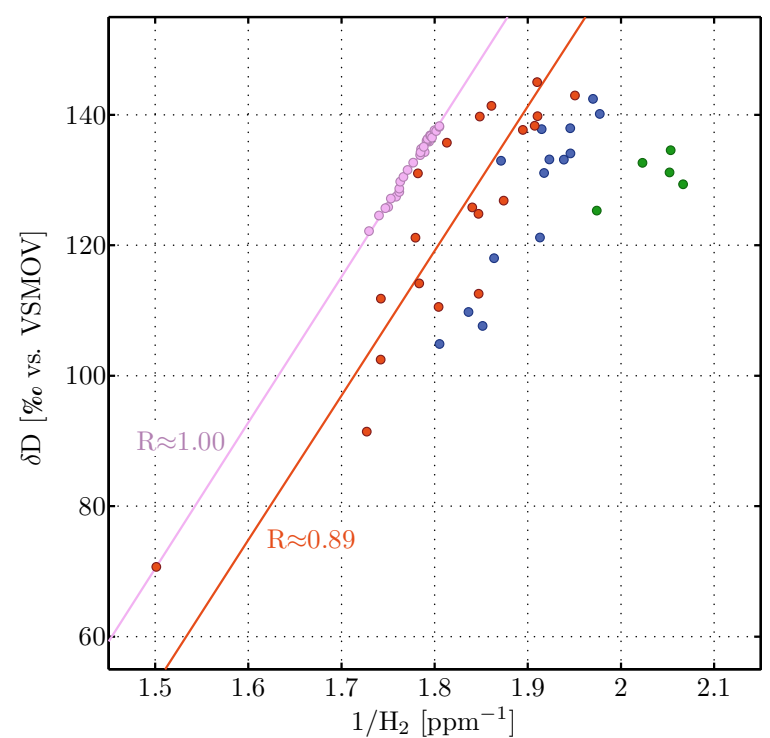

- Samples $>1100 \mathrm{~m}$ a.s.l.: $\delta \mathrm{D}=\left[222( \pm 13) \mathrm{H}_{2}^{-1}-280( \pm 41)\right] \%$ o

- Samples $<1100 \mathrm{~m}$ a.s.l.

- Samples with strong influence of soil uptake

- TM5 Region, $\sim 1300 \mathrm{~m}$ a.s.l.: $\delta \mathrm{D}=\left[224( \pm 62) \mathrm{H}_{2}^{-1}-265( \pm 9)\right] \%$ o

Fig. 3. Keeling plot showing $\delta \mathrm{D}$ versus the inverse mixing ratio of $\mathrm{H}_{2}$. The same colour scheme as in Fig. 2 is used to classify the BARCA-A samples. The Keeling plot returns an $y$-axis intercept of $-280 \pm 41 \%$ as isotopic signature of the contaminating source. The regression line (red) is derived with a bivariate total least square fitting technique. Pearson's correlation coefficient for all samples above $1100 \mathrm{~m}$ a.s.l. yields a value of -0.89 and is significant at a $99 \%$ confidence level. The pink points that show TM5 results at about $1300 \mathrm{~m}$ a.s.l. are from Fig. 4. Regression analysis for these points results in a $\delta \mathrm{D}_{\mathrm{bb}}$ signature of $-265 \%$ o which is close to the model input value at the surface of $-262 \%$.

So far, three independent estimates of $\delta \mathrm{D}_{\mathrm{bb}}$ exist (cf. Table 2). Gerst and Quay (2001) estimate the global average $\delta \mathrm{D}_{\mathrm{bb}}$ with $-290 \pm 60 \%$ from experimental fire measurements by burning pine needles and branches that were, subsequently, extrapolated to a global scale. A similar overall value of $-262 \pm 27 \%$ o is given by Röckmann et al. (2010a) who performed combustion experiments under varying conditions with many wood samples from different locations. Even though this result has not been extrapolated to a global scale, it confirms the estimate by Gerst and Quay (2001). In contrast, the global mean $\delta \mathrm{D}_{\mathrm{bb}}$ derived by Rhee et al. (2006) is, with a value of $-90 \pm 40 \%$, much higher. Röckmann et al. (2010a) do not find a relation between $\delta \mathrm{D}_{\mathrm{bb}}$ and the $\Delta \mathrm{H}_{2} / \Delta \mathrm{CO}$ ratio that was used by Rhee et al. (2006) to derive their estimate of the global mean signature.

The regional $\delta \mathrm{D}_{\mathrm{bb}}$ depends mainly on the latitude due the variations of $\delta \mathrm{D}$ in the precipitation, on the combustion efficiency, and the plant type. The precipitation effect leads to an enriched $\delta \mathrm{D}_{\mathrm{bb}}$ in the tropics compared to the global 
a)

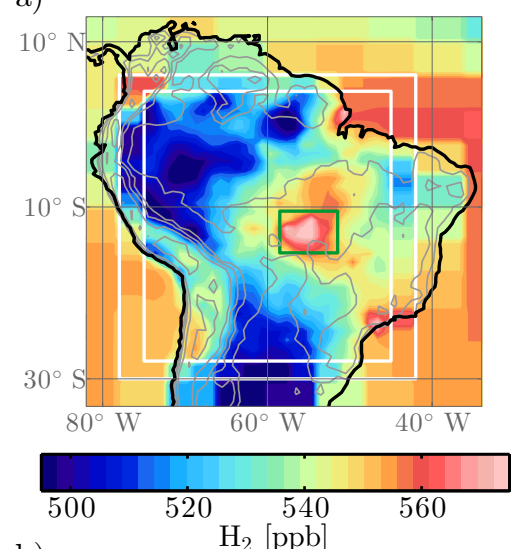

b)

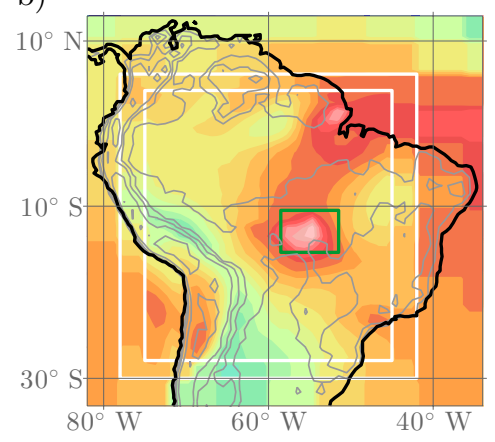

c)

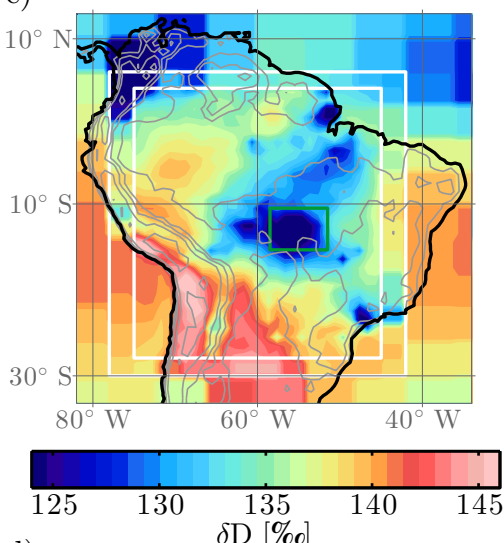

d)

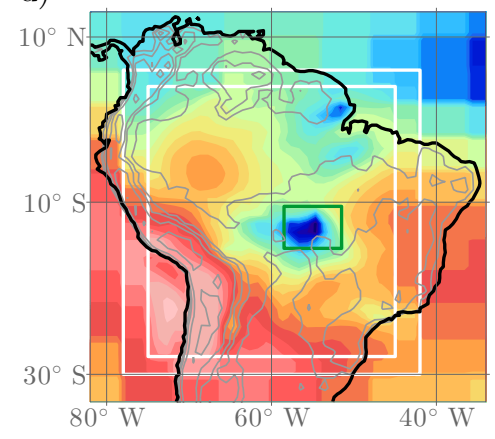

e)

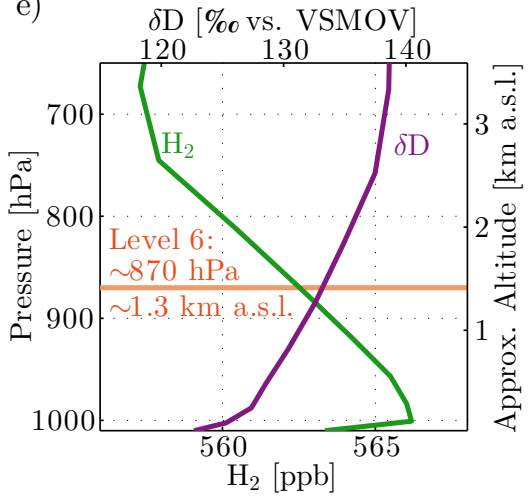

f)

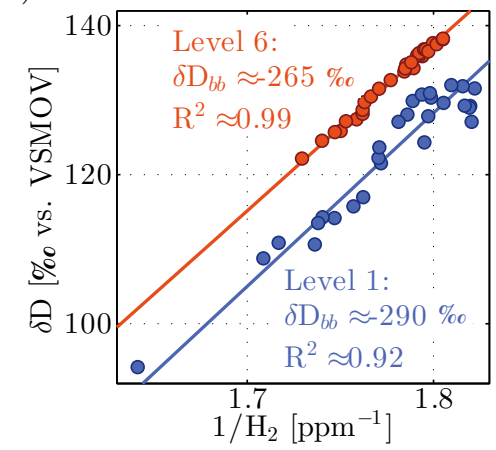

Fig. 4. TM5 results for November and December after five years of integration from the zoom region over the Amazon Basin (white boxes in panels (a) through (d) indicate the boundary of the respective resolutions). Surface emissions are from the year 2003 with a distinct biomass-burning source indicated by the green box in the centre of the domain (panels a through d). Mean $\mathrm{H}_{2}$ mixing ratios (a) and (b), and $\delta \mathrm{D}$ values (c) and (d) of the lowest (level one, top panels) and sixth lowest (level six, bottom panels) atmospheric model levels. Level six of the model corresponds to about $870 \mathrm{hPa}$ or $1.3 \mathrm{~km}$ a.s.l. (e) Vertical profiles of $\mathrm{H}_{2}$ and $\delta \mathrm{D}$ from the spatial mean of the green box. (f) Keeling plot with regression lines of all grid cell values within the green box for level one (blue) and level six (red). The values from level six show the $\delta \mathrm{D}_{\mathrm{bb}}$ signature closest to the input value of $-262 \%$ and the highest correlation.

mean value (Röckmann et al., 2010a). The combustion efficiency is extremely variable between different ecosystems, seasons, primary and secondary forests, and natural and anthropogenic fires (Seiler and Crutzen, 1980); it is determined (among other factors) by the availability of oxygen and the temperature of the combustion process (Röckmann et al., 2010a). In terms of plant type, $\mathrm{C} 3$ plants are depleted in $\delta \mathrm{D}$ compared to C4 plants (Leaney et al., 1985; Vigano et al., 2009, 2010).

The isotopic biomass-burning signature from the selected BARCA-A samples of $-280 \pm 41 \%$ is in line with the estimates given by Gerst and Quay (2001) and Röckmann et al. (2010a) that were retrieved from combustion experiments (cf. Table 2). The comparatively high $\delta \mathrm{D}$ values of the precipitation at lower latitudes would result in a slightly higher estimate from our samples than the global mean value. Figure 6 of the study by Röckmann et al. (2010a) suggests that this latitudinal effect in the biomass results in about 10 to $20 \%$ o higher $\delta \mathrm{D}$ values than the global mean. However, this effect lies within the range of uncertainty that we provide.
We conclude that the isotopic biomass-burning signature provided by Rhee et al. (2006) for tropical rainforest is too high and values are rather within the suggested range by Gerst and Quay (2001) and Röckmann et al. (2010a).

\section{Vertical structure of the biomass-burning signature in the model simulation}

By analysing the model output from the TM5 simulation for the Amazon Basin as described in Sect. 2.4, we aim to verify our approach to separate the samples by altitude. We expect to obtain a similar signal as in the observations in a region of biomass burning, thus a mixture of the soil uptake and biomass-burning source signals close to the ground and a signal dominated by biomass burning above the atmospheric boundary layer. We do not attempt to provide a model-observations intercomparison since we use surface emissions from the year 2003. Here, we rather aim to support our analysis by studying how turbulent mixing in the 
boundary layer and vertical transport by convection change the vertical profiles of $\mathrm{H}_{2}$ and $\delta \mathrm{D}$ and distort the $\delta \mathrm{D}_{\mathrm{bb}}$ signal.

Figure 4a shows the TM5 zoom region over the Amazon Basin and the mean $\mathrm{H}_{2}$ mixing ratio in the atmospheric surface layer for the months November and December after five years of integration. One should keep in mind that due to the different surface emissions, biomass-burning regions will not coincide with those displayed in Fig. 1. However, meteorological conditions should be representative for the vertical transport and boundary layer mixing during that time of the year. In the centre of the domain there is an area of highly elevated $\mathrm{H}_{2}$ mixing ratios that are clearly the result of biomass burning (indicated by the green box). Furthermore, it should be noticed that this region is at a different location to the sampling region (cf. Fig. 1b) with, probably, a very different vegetation cover (mixed grassland, secondary forest, and rainforest; Saatchi et al., 2007; Simon et al., 2009). However, this will not affect our results since the model does not distinguish $\mathrm{C} 3$ and $\mathrm{C} 4$ plants in terms of their $\delta \mathrm{D}$ signature, which has a fixed input value for biomass burning of $-262 \%$.

The sixth model level at about $870 \mathrm{hPa}$ (about $1300 \mathrm{~m}$ a.s.l.) in this region is just above the altitude of $1100 \mathrm{~m}$ a.s.l. that we determined to be optimal for the separation of the samples in Sect. 3. At this altitude the mean $\mathrm{H}_{2}$ mixing ratio is almost everywhere fairly constant with values between 540 and $560 \mathrm{ppb}$ (Fig. 4b). A mixing ratio of $560 \mathrm{ppb}$ is only exceeded in the mentioned biomass-burning region and in another region close to the coast towards the north-east of the domain that is also influenced by biomass burning. While the biomass-burning signal is clearly present, we expect that the direct impact of surface deposition vanishes at an altitude of $1300 \mathrm{~m}$ a.s.l. The same effect is visible when considering the $\mathrm{H}_{2}$ isotopic composition shown in Fig. $4 \mathrm{c}$ and $\mathrm{d}$ for the two model levels with strongly depleted values in the indicated region.

The average vertical profiles of $\mathrm{H}_{2}$ and $\delta \mathrm{D}$ for the region within the green box (cf. Fig. 4e) show elevated $\mathrm{H}_{2}$ mixing ratios and lower $\delta \mathrm{D}$ values up to a height of about $700 \mathrm{hPa}$ (or about $3000 \mathrm{~m}$ a.s.1.), indicating a high reaching effect of the biomass burning. Within the surface layer, below $1000 \mathrm{hPa}$, the $\mathrm{H}_{2}$ mixing ratio is strongly depleted by the soil uptake of $\mathrm{H}_{2}$ leaving a peak mixing ratio at $1000 \mathrm{hPa}$. At higher altitudes the biomass-burning signal dominates. We propose that deep and shallow convection over the tropical South American continent carries the biomass-burning signal to an altitude of $1000 \mathrm{~m}$ a.s.l. and higher. In the TM5 model, we emit $40 \%$ of the biomass burning emissions between 1000 and $2000 \mathrm{~m}$ a.s.l. to account for plume rise above the most intensive fires. The $60 \%$ emitted at lower altitudes, however, stay within the atmospheric boundary layer. Turbulence repeatedly mixes the air to the surface and, thus, allows the soil uptake to alter the biomass-burning signal.

The influence of the soil uptake on the vertical $\mathrm{H}_{2}$ mixing ratio profile apparent in the simulation likely also influenced the BARCA-A samples. It is very likely the reason for the lower $\Delta \mathrm{H}_{2} / \Delta \mathrm{CO}$ ratio in the lower altitude samples (cf. Sect. 3). A vertical discrepancy in the $\Delta \mathrm{H}_{2} / \Delta \mathrm{CO}$ ratio is also reported by Popa et al. (2011) who find an influence of altitude on the ratio from fossil-fuel-burning source and conclude that atmospheric mixing and the soil uptake close to the ground might be responsible.

We further test our hypothesis by comparing the known model input value for $\delta \mathrm{D}_{\mathrm{bb}}$ of $-262 \%$ to a Keeling plot analysis of samples from each model level (Fig. 4f). The regression analysis is performed through all grid points within the green box. In the surface layer (blue line in Fig. 4f), the data points seem to carry a biomass-burning signature. However, the Keeling plot intercept is with $-290 \%$ o somewhat lower than the original source value of $-262 \%$ o that was applied in the model. This discrepancy may be caused by interfering effects from the soil sink near the surface, for example. If we perform the Keeling plot analysis at higher model levels, the intercept increases towards the input value. At the sixth model level, the value $(-265 \%$ ) is the closest to the input value $(-262 \%)$ and the correlation coefficient between $\delta \mathrm{D}_{\mathrm{bb}}$ and the inverse $\mathrm{H}_{2}$ mixing ratio is highest (cf. red line in Fig. 4f). This confirms that at this level the distortion of the biomass-burning signal by the soil uptake has nearly vanished completely and that the fixed input value for the biomass-burning emissions at the surface can be recovered at this altitude.

Comparing these observations to our selection procedure of Sects. 3 and 4 suggests that the actual separation level of $1100 \mathrm{~m}$ a.s.l. is reasonable in terms of vertical transport. The regression line from the sixth level of the model region is also added in Fig. 3. The offset between the lines of best fit (purple and red) results from the slightly different input signature in the model of $-262 \%$ compared to the value of $-280 \pm 41 \%$ o that we derive for the tropical biomass burning from the measurements. Furthermore, the slope of the regression line is almost identical and within the range of uncertainty. Because of these two latter findings and the fact that the model derived biomass-burning signature is very close to the model forcing value, we are confident that the signal retrieved from the selected BARCA-A samples is a pure biomass-burning signature and that our approach is justified.

From both Figs. 3 and 4f, we conclude that closer to the ground the isotopic biomass-burning signature would be biased by the soil uptake towards lower $\delta \mathrm{D}_{\mathrm{bb}}$ values. This is the result of a shift in the $\mathrm{H}_{2}$ mixing ratio towards lower values (to the right along the $x$ axis in the Keeling plot) when $\mathrm{H}_{2}$ is continuously deposited at the surface. As a consequence, the $y$ axis intercept is shifted towards lower values resulting in an apparent lower isotopic biomass-burning signature.

\section{Summary and conclusions}

During the BARCA-LBA project air samples were collected over the Amazonian tropical rainforest during the dry season 
in regions of extensive biomass burning or downwind of these regions at different altitudes. We have measured the mixing ratios of several species and the isotopic composition of $\mathrm{H}_{2}$ of 39 air samples. From these measurements, we have derived a signal of the biomass-burning source that can be used to estimate $\mathrm{H}_{2}$ emissions from tropical forest fires and better constrain global chemistry models. We have determined the $\Delta \mathrm{H}_{2} / \Delta \mathrm{CO}$ ratio, on the one hand, and the isotopic signature of $\mathrm{H}_{2}$, on the other hand, to characterise the biomass-burning source signal.

For the analysis, the samples have been separated into groups of higher and lower altitude in order to avoid an interfering signal from the soil uptake of $\mathrm{H}_{2}$. Mixing in the lower boundary layer leads to lower $\mathrm{H}_{2}$ mixing ratios in those samples due to soil uptake. In contrast, the strong convection induced by the heat from the fires and the naturally unstable boundary layer results in high-reaching biomass-burning plumes. This enabled us to derive the signal from the samples collected at higher altitudes. We have obtained best results when using an altitude of $1100 \mathrm{~m}$ a.s.l. for the separation. A group of samples with very low $\mathrm{H}_{2}$ mixing ratios has been separated from the analysis as they are probably strongly influenced by the soil uptake.

The selection of the samples from higher altitude yielded a high and significant correlation coefficient of 0.95 between the $\mathrm{CO}$ and $\mathrm{H}_{2}$ mixing ratio and thus provides a clear biomass-burning signal. From these samples, we have derived a $\Delta \mathrm{H}_{2} / \Delta \mathrm{CO}$ emission ratio of $0.31 \pm 0.04$. The correlation coefficient from the lower altitude samples is lower. This implies an influence of the $\mathrm{H}_{2}$ uptake process by the soil.

We have studied the isotopic composition in the same selection of samples from the top of the boundary layer. A Keeling plot of these samples shows a signal from biomass burning in the Amazonian tropical rainforest with an isotopic source signature $\delta \mathrm{D}_{\mathrm{bb}}=-280 \pm 41 \%$. The $\delta \mathrm{D}$ values and the inverse of the $\mathrm{H}_{2}$ mixing ratio correlate significantly with a coefficient of -0.89 . The biomass-burning signal identified by Beck et al. (2012) in the methane isotopic composition of a sample that was collected while the airplane was flying through a dense plume is also visible in our results.

From simulations with a chemistry transport model we have obtained a comparable vertical structure of the biomassburning signal with an interfering signal from the soil uptake of $\mathrm{H}_{2}$ closer to the ground likely due to vertical mixing to the surface. At an altitude of about $1300 \mathrm{~m}$ a.s.l. $\delta \mathrm{D}_{\mathrm{bb}}$ converges to the imposed biomass-burning signature and to the highest correlation between $\delta \mathrm{D}$ and the inverse $\mathrm{H}_{2}$ mixing ratio. The air masses at these high altitudes are only influenced by the biomass-burning source since presumably convection transported the signal to the free troposphere and the soil-sink process has vanished. The model results confirm our approach to separate the samples and also the selected altitude.

Our results suggest that earlier estimates of the $\Delta \mathrm{H}_{2} / \Delta \mathrm{CO}$ ratio from biomass burning over the tropical rainforest (Andreae and Merlet, 2001; Rhee et al., 2006) are probably too high. This should be further examined with additional measurements. Moreover, the $\delta \mathrm{D}_{\mathrm{bb}}$ signature from the tropical rainforest is much lower than the estimate by Rhee et al. (2006) and confirms the range of values suggested by Gerst and Quay (2001) and Röckmann et al. (2010a).

\section{Supplementary material related to this article is available online at http://www.atmos-chem-phys.net/13/ 9401/2013/acp-13-9401-2013-supplement.zip.}

Acknowledgements. We are very thankful to all institutions that have participated in the BARCA-LBA campaign and contributed to the data sampling. In particular, we would like to thank A. Jordan, J. Steinbach, H. Chen, O. Kolle, and M. Rothe from the Max Planck Institute for Biogeochemistry in Jena (Germany) for the sample collection and compound mixing ratio measurements. We appreciate the contribution of the LBA/BARCA team members P. Celso, D. Gramacho, P. Artaxo, F. Moraes, A. Camargo Ribeiro, S. Freitas, K. Longo, K. Wiedemann, M. Longo, V. Chow, B. Daube, E. Gottlieb, M. de Silva Dias, L. Gatti, M. Andreae, M. Welling, and N. Jürgens. The funding for the BARCA flight campaign was provided by the Max Planck Society, the NASA and the Millennium Institute of the Brazilian Large Scale Biosphere - Atmosphere Experiment (LBA). The isotope measurements were funded by the NWO (Netherlands Organisation for Scientific Research), project numbers 053.61.026 and 816.01.00. We would like to thank the participants of the IMPRS writing workshop with D. Murphy and J. Marotzke for their valuable comments on an earlier manuscript.

Edited by: A. Engel

\section{References}

Andreae, M. O. and Merlet, P.: Emission of trace gases and aerosols from biomass burning, Global Biogeochem. Cy., 15, 955-966, doi:10.1029/2000GB001382, 2001.

Andreae, M. O., Artaxo, P., Beck, V., Bela, M., Freitas, S., Gerbig, C., Longo, K., Munger, J. W., Wiedemann, K. T., and Wofsy, S. C.: Carbon monoxide and related trace gases and aerosols over the Amazon Basin during the wet and dry seasons, Atmos. Chem. Phys., 12, 6041-6065, doi:10.5194/acp-12-6041-2012, 2012.

Batenburg, A. M., Walter, S., Pieterse, G., Levin, I., Schmidt, M., Jordan, A., Hammer, S., Yver, C., and Röckmann, T.: Temporal and spatial variability of the stable isotopic composition of atmospheric molecular hydrogen: observations at six EUROHYDROS stations, Atmos. Chem. Phys., 11, 6985-6999, doi:10.5194/acp11-6985-2011, 2011.

Batenburg, A. M., Schuck, T. J., Baker, A. K., Zahn, A., Brenninkmeijer, C. A. M., and Röckmann, T.: The stable isotopic composition of molecular hydrogen in the tropopause region probed by the CARIBIC aircraft, Atmos. Chem. Phys., 12, 46334646, doi:10.5194/acp-12-4633-2012, 2012. 
Beck, V., Chen, H., Gerbig, C., Bergamaschi, P., Bruhwiler, L., Houweling, S., Röckmann, T., Kolle, O., Steinbach, J., Koch, T., Sapart, C. J., van der Veen, C., Frankenberg, C., Andreae, M. O., Artaxo, P., Longo, K. M., and Wofsy, S. C.: Methane airborne measurements and comparison to global models during BARCA, J. Geophys. Res.-Atmos., 117, D15310, doi:10.1029/2011JD017345, 2012.

Cantrell, C. A.: Technical Note: Review of methods for linear leastsquares fitting of data and application to atmospheric chemistry problems, Atmos. Chem. Phys., 8, 5477-5487, doi:10.5194/acp8-5477-2008, 2008.

Chen, H., Winderlich, J., Gerbig, C., Hoefer, A., Rella, C. W., Crosson, E. R., Van Pelt, A. D., Steinbach, J., Kolle, O., Beck, V., Daube, B. C., Gottlieb, E. W., Chow, V. Y., Santoni, G. W., and Wofsy, S. C.: High-accuracy continuous airborne measurements of greenhouse gases $\left(\mathrm{CO}_{2}\right.$ and $\left.\mathrm{CH}_{4}\right)$ using the cavity ringdown spectroscopy (CRDS) technique, Atmos. Meas. Tech., 3, 375-386, doi:10.5194/amt-3-375-2010, 2010.

Chen, H., Winderlich, J., Gerbig, C., Katrynski, K., Jordan, A., and Heimann, M.: Validation of routine continuous airborne $\mathrm{CO}_{2}$ observations near the Bialystok Tall Tower, Atmos. Meas. Tech., 5, 873-889, doi:10.5194/amt-5-873-2012, 2012.

Crutzen, P. J., Heidt, L. E., Krasnec, J. P., Pollock, W. H., and Seiler, W.: Biomass burning as a source of atmospheric gases $\mathrm{CO}, \mathrm{H}_{2}, \mathrm{~N}_{2} \mathrm{O}, \mathrm{NO}, \mathrm{CH}_{3} \mathrm{Cl}$ and $\mathrm{COS}$, Nature, 282, 253-256, doi:10.1038/282253a0, 1979 .

Dee, D. P., Uppala, S. M., Simmons, A. J., Berrisford, P., Poli, P., Kobayashi, S., Andrae, U., Balmaseda, M. A., Balsamo, G., Bauer, P., Bechtold, P., Beljaars, A. C. M., van de Berg, L., Bidlot, J., Bormann, N., Delsol, C., Dragani, R., Fuentes, M., Geer, A. J., Haimberger, L., Healy, S. B., Hersbach, H., Hólm, E. V., Isaksen, L., Kållberg, P., Köhler, M., Matricardi, M., McNally, A. P., Monge-Sanz, B. M., Morcrette, J.-J., Park, B.-K., Peubey, C., de Rosnay, P., Tavolato, C., Thépaut, J.-N., and Vitart, F.: The ERA-Interim reanalysis: configuration and performance of the data assimilation system, Q. J. Roy. Meteor. Soc., 137, 553-597, doi:10.1002/qj.828, 2011.

Derwent, R., Simmonds, P., O’Doherty, S., Manning, A., Collins, W., and Stevenson, D.: Global environmental impacts of the hydrogen economy, Int. J. Nucl. Hydrogen Prod. Appl., 1, 57-67, 2006.

de Wit, J. C., van der Straaten, C. M., and Mook, W. G.: Determination of the Absolute Hydrogen Isotopic Ratio of V-SMOW and SLAP, Geostandard. Newslett., 4, 33-36, doi:10.1111/j.1751908X.1980.tb00270.x, 1980.

Ehhalt, D. H.: Gas Phase Chemistry of the Troposphere, in: Global Aspects of Atmospheric Chemistry, in: Topics in Physical Chemistry, vol. 6, edited by: Zellner, R., Steinkopff, Darmstadt, 21109, 1999.

Ehhalt, D. H. and Rohrer, F.: The tropospheric cycle of $\mathrm{H}_{2}$ : a critical review, Tellus B, 61, 500-535, doi:10.1111/j.16000889.2009.00416.x, 2009.

$\mathrm{Fu}, \mathrm{R}$. and $\mathrm{Li}, \mathrm{W}$. : The influence of the land surface on the transition from dry to wet season in Amazonia, Theor. Appl. Climatol., 78, 97-110, doi:10.1007/s00704-004-0046-7, 2004.

Fu, R., Zhu, B., and Dickinson, R. E.: How Do Atmosphere and Land Surface Influence Seasonal Changes of Convection in the Tropical Amazon?, J. Climate, 12, 1306-1321,
doi:10.1175/1520-0442(1999)012<1306:HDAALS>2.0.CO;2, 1999.

Gerst, S. and Quay, P.: Deuterium component of the global molecular hydrogen cycle, J. Geophys. Res.-Atmos., 106, 5021-5031, doi:10.1029/2000JD900593, 2001.

Gonfiantini, R., Stichler, W., and Rozanski, K.: Standards and intercomparison materials distributed by the International Atomic Energy Agency for stable isotope measurements, in Reference and intercomparison materials for stable isotopes of light elements: Proceedings of a consultants meeting held in Vienna, 1-3 December 1993, IAEA-TECDOC-825, International Atomic Energy Agency, 1993.

Hauglustaine, D. A. and Ehhalt, D. H.: A three-dimensional model of molecular hydrogen in the troposphere, J. Geophys. Res.Atmos., 107, 4330, doi:10.1029/2001JD001156, 2002.

Huijnen, V., Williams, J., van Weele, M., van Noije, T., Krol, M., Dentener, F., Segers, A., Houweling, S., Peters, W., de Laat, J., Boersma, F., Bergamaschi, P., van Velthoven, P., Le Sager, P., Eskes, H., Alkemade, F., Scheele, R., Nédélec, P., and Pätz, H.-W.: The global chemistry transport model TM5: description and evaluation of the tropospheric chemistry version 3.0, Geosci. Model Dev., 3, 445-473, doi:10.5194/gmd-3-445-2010, 2010.

Jordan, A. and Steinberg, B.: Calibration of atmospheric hydrogen measurements, Atmos. Meas. Tech., 4, 509-521, doi:10.5194/amt-4-509-2011, 2011.

Kaiser, J. W., Heil, A., Andreae, M. O., Benedetti, A., Chubarova, N., Jones, L., Morcrette, J.-J., Razinger, M., Schultz, M. G., Suttie, M., and van der Werf, G. R.: Biomass burning emissions estimated with a global fire assimilation system based on observed fire radiative power, Biogeosciences, 9, 527-554, doi:10.5194/bg-9-527-2012, 2012.

Krol, M., Houweling, S., Bregman, B., van den Broek, M., Segers, A., van Velthoven, P., Peters, W., Dentener, F., and Bergamaschi, P.: The two-way nested global chemistry-transport zoom model TM5: algorithm and applications, Atmos. Chem. Phys., 5, 417 432, doi:10.5194/acp-5-417-2005, 2005.

Laursen, K. K., Hobbs, P. V., Radke, L. F., and Rasmussen, R. A.: Some trace gas emissions from North American biomass fires with an assessment of regional an global fluxes from biomass burning, J. Geophys. Res.-Atmos., 97, 20687-20701, doi:10.1029/92JD02168, 1992.

Leaney, F. W., Osmond, C. B., Allison, G. B., and Ziegler, H.: Hydrogen-isotope composition of leaf water in $\mathrm{C} 3$ and $\mathrm{C} 4$ plants: its relationship to the hydrogen-isotope composition of dry matter, Planta, 164, 215-220, doi:10.1007/BF00396084, 1985.

Miller, J. B., Gatti, L. V., d'Amelio, M. T. S., Crotwell, A. M., Dlugokencky, E. J., Bakwin, P., Artaxo, P., and Tans, P. P.: Airborne measurements indicate large methane emissions from the eastern Amazon basin, Geophys. Res. Lett., 34, L10809, doi:10.1029/2006GL029213, 2007.

Novelli, P. C., Lang, P. M., Masarie, K. A., Hurst, D. F., Myers, R., and Elkins, J. W.: Molecular hydrogen in the troposphere: Global distribution and budget, J. Geophys. Res.-Atmos., 104, 30427-30444, doi:10.1029/1999JD900788, 1999.

Novelli, P. C., Masarie, K. A., Lang, P. M., Hall, B. D., Myers, R. C., and Elkins, J. W.: Reanalysis of tropospheric CO trends: Effects of the 1997-1998 wildfires, J. Geophys. Res.-Atmos., 108, 4464, doi:10.1029/2002JD003031, 2003. 
Pieterse, G., Krol, M. C., Batenburg, A. M., Steele, L. P., Krummel, P. B., Langenfelds, R. L., and Röckmann, T.: Global modelling of $\mathrm{H}_{2}$ mixing ratios and isotopic compositions with the TM5 model, Atmos. Chem. Phys., 11, 7001-7026, doi:10.5194/acp-11-70012011, 2011.

Pieterse, G., Krol, M. C., Batenburg, A. M., Brenninkmeijer, C. A. M., Popa, M. E., O’Doherty, S., Grant, A., Steele, L. P., Krummel, P. B., Langenfelds, R. L., Wang, H. J., Vermeulen, A. T., Schmidt, M., Yver, C., Jordan, A., Engel, A., Fisheraffilmark, R. E., Lowry, D., Nisbet, E. G., Reimann, S., Vollmer, M. K., Steinbacher, M., Hammer, S., Forster, G., Sturges, W. T., and Röckmann, T.: Reassessing the variability in atmospheric $\mathrm{H}_{2}$ using the two-way nested TM5 model, J. Geophys. Res.-Atmos., 118, 3764-3780, doi:10.1002/jgrd.50204, 2013.

Popa, M. E., Vermeulen, A. T., van den Bulk, W. C. M., Jongejan, P. A. C., Batenburg, A. M., Zahorowski, W., and Röckmann, T.: $\mathrm{H}_{2}$ vertical profiles in the continental boundary layer: measurements at the Cabauw tall tower in The Netherlands, Atmos. Chem. Phys., 11, 6425-6443, doi:10.5194/acp-11-6425-2011, 2011.

Price, H., Jaeglé, L., Rice, A., Quay, P., Novelli, P. C., and Gammon, R.: Global budget of molecular hydrogen and its deuterium content: Constraints from ground station, cruise, and aircraft observations, J. Geophys. Res.-Atmos., 112, D22108, doi:10.1029/2006JD008152, 2007.

Rhee, T. S., Mak, J., Röckmann, T., and Brenninkmeijer, C. A. M.: Continuous-flow isotope analysis of the deuterium/hydrogen ratio in atmospheric hydrogen, Rapid Commun. Mass Sp., 18, 299306, doi:10.1002/rcm.1309, 2004.

Rhee, T. S., Brenninkmeijer, C. A. M., and Röckmann, T.: The overwhelming role of soils in the global atmospheric hydrogen cycle, Atmos. Chem. Phys., 6, 1611-1625, doi:10.5194/acp-61611-2006, 2006.

Röckmann, T., Kaiser, J., Brenninkmeijer, C. A. M., and Brand, W. A.: Gas chromatography/isotope-ratio mass spectrometry method for high-precision position-dependent ${ }^{15} \mathrm{~N}$ and ${ }^{18} \mathrm{O}$ measurements of atmospheric nitrous oxide, Rapid Commun. Mass Sp., 17, 1897-1908, doi:10.1002/rcm.1132, 2003.

Röckmann, T., Gómez Álvarez, C. X., Walter, S., van der Veen, C., Wollny, A. G., Gunthe, S. S., Helas, G., Pöschl, U., Keppler, F., Greule, M., and Brand, W. A.: Isotopic composition of $\mathrm{H}_{2}$ from wood burning: Dependency on combustion efficiency, moisture content, and $\delta \mathrm{D}$ of local precipitation, J. Geophys. Res.-Atmos., 115, D17308, doi:10.1029/2009JD013188, 2010a.

Röckmann, T., Walter, S., Bohn, B., Wegener, R., Spahn, H., Brauers, T., Tillmann, R., Schlosser, E., Koppmann, R., and Rohrer, F.: Isotope effect in the formation of $\mathrm{H}_{2}$ from $\mathrm{H}_{2} \mathrm{CO}$ studied at the atmospheric simulation chamber SAPHIR, Atmos. Chem. Phys., 10, 5343-5357, doi:10.5194/acp-10-53432010, 2010b.

Saatchi, S. S., Houghton, R. A., Dos Santos Alvalá, R. C., Soares, J. V., and Yu, Y.: Distribution of aboveground live biomass in the Amazon basin, Glob. Change Biol., 13, 816-837, doi:10.1111/j.1365-2486.2007.01323.x, 2007.

Schultz, M. and Stein, O.: GEMS (GRG) emissions for 2003 reanalysis simulations, Tech. rep., Max Planck Institute for Meteorology, Hamburg, Germany, 2006.
Schultz, M. G., Diehl, T., Brasseur, G. P., and Zittel, W.: Air Pollution and Climate-Forcing Impacts of a Global Hydrogen Economy, Science, 302, 624-627, doi:10.1126/science.1089527, 2003.

Seiler, W. and Crutzen, P. J.: Estimates of gross and net fluxes of carbon between the biosphere and the atmosphere from biomass burning, Climatic Change, 2, 207-247, doi:10.1007/BF00137988, 1980.

Simmonds, P. G., Derwent, R. G., O'Doherty, S., Ryall, D. B., Steele, L. P., Langenfelds, R. L., Salameh, P., Wang, H. J., Dimmer, C. H., and Hudson, L. E.: Continuous high-frequency observations of hydrogen at the Mace Head baseline atmospheric monitoring station over the 1994-1998 period, J. Geophys. Res.Atmos., 105, 12105-12121, doi:10.1029/2000JD900007, 2000.

Simon, M. F., Grether, R., de Queiroz, L. P., Skema, C., Pennington, R. T., and Hughes, C. E.: Recent assembly of the Cerrado, a neotropical plant diversity hotspot, by in situ evolution of adaptations to fire, P. Natl. Acad. Sci. USA, 106, 20359-20364, doi:10.1073/pnas.0903410106, 2009.

Stull, R.: An Introduction to Boundary Layer Meteorology, Atmospheric Sciences Library, Kluwer Academic Publishers, Dordrecht, Boston, London, 1988.

Vigano, I., Röckmann, T., Holzinger, R., van Dijk, A., Keppler, F., Greule, M., Brand, W. A., Geilmann, H., and van Weelden, H.: The stable isotope signature of methane emitted from plant material under UV irradiation, Atmos. Environ., 43, 5637-5646, doi:10.1016/j.atmosenv.2009.07.046, 2009.

Vigano, I., Holzinger, R., Keppler, F., Greule, M., Brand, W. A., Geilmann, H., van Weelden, H., and Röckmann, T.: Water drives the deuterium content of the methane emitted from plants, Geochim. Cosmochim. Ac., 74, 3865-3873, doi:10.1016/j.gca.2010.03.030, 2010.

Vollmer, M. K., Walter, S., Mohn, J., Steinbacher, M., Bond, S. W., Röckmann, T., and Reimann, S.: Molecular hydrogen $\left(\mathrm{H}_{2}\right)$ combustion emissions and their isotope $(\mathrm{D} / \mathrm{H})$ signatures from domestic heaters, diesel vehicle engines, waste incinerator plants, and biomass burning, Atmos. Chem. Phys., 12, 6275-6289, doi:10.5194/acp-12-6275-2012, 2012.

Xiao, X., Prinn, R. G., Simmonds, P. G., Steele, L. P., Novelli, P. C., Huang, J., Langenfelds, R. L., O'Doherty, S., Krummel, P. B., Fraser, P. J., Porter, L. W., Weiss, R. F., Salameh, P., and Wang, R. H. J.: Optimal estimation of the soil uptake rate of molecular hydrogen from the Advanced Global Atmospheric Gases Experiment and other measurements, J. Geophys. Res.-Atmos., 112, D07303, doi:10.1029/2006JD007241, 2007.

Yver, C. E., Pison, I. C., Fortems-Cheiney, A., Schmidt, M., Chevallier, F., Ramonet, M., Jordan, A., Søvde, O. A., Engel, A., Fisher, R. E., Lowry, D., Nisbet, E. G., Levin, I., Hammer, S., Necki, J., Bartyzel, J., Reimann, S., Vollmer, M. K., Steinbacher, M., Aalto, T., Maione, M., Arduini, J., O’Doherty, S., Grant, A., Sturges, W. T., Forster, G. L., Lunder, C. R., Privalov, V., Paramonova, N., Werner, A., and Bousquet, P.: A new estimation of the recent tropospheric molecular hydrogen budget using atmospheric observations and variational inversion, Atmos. Chem. Phys., 11, 3375-3392, doi:10.5194/acp-11-3375-2011, 2011. 